\title{
EL LÍMITE DE COPIA PRIVADA. EVOLUCIÓN HISTÓRICA Y CONSTRUCCIÓN ACTUAL*
}

\author{
THE PRIVATE COPYING LIMIT, HISTORICAL EVOLUTION AND CURRENT \\ CONSTRUTION
}

\author{
JAVIER FERNÁNDEZ-LASQUETTY MARTÍN**
}

\begin{abstract}
Resumen: El límite de copia privada y su sistema de es uno de los asuntos más controvertidos y polémicos dentro de la regulación de la Propiedad Intelectual. Esto se debe a la cantidad de intereses en juego y a la obligación de cumplir con las directrices de la Unión Europea en esta materia. Consiste en la posibilidad que tienen los particulares de realizar copias de obras protegidas para su uso privado. Se realizará un análisis de la evolución que este precepto ha tenido a lo largo del tiempo y la construcción, así como los requisitos que la ley impone hoy día para que una reproducción sea amparada por este límite con el objetivo de dilucidar por qué el límite es hoy como es y el futuro que le espera.
\end{abstract}

Palabras Clave: límite, reproducción, derechohabientes, uso privado, regla de los tres pasos.

Abstract: Due to the interest at stake and the obligation to comply EU guidelines, the scope of private copying is one of the most controversial issues when regulating Intellectual Property. Private copying is the individual's possibility to copy works protected under copyright for his private use. In this study, I will analyze the evolution of this precept throughout time and construction, as well as the requirements imposed by law for a reproduction to be sheltered in order to elucidate why the scope is how it is today and what can we expect for the future.

Keywords: private copying limit, reproduction, rightful owner, private use, three-step test.

SUMARIO: I. INTRODUCCIÓN; II. NATURALEZA Y JUSTIFICACIÓN; III. EVOLUCIÓN HISTÓRICA DEL LÍMITE DE COPIA PRIVADA; 1. 1987-2006; 2. 2006-2011 y el caso Padawan; 3. 2011-2017 y el caso EGEDA y otros; IV. CONSTRUCCIÓN ACTUAL DEL LÍMITE DE COPIA PRIVADA; 1 . Sobre cualquier soporte; 2 . Sin la asistencia de terceros; 3. De obras ya divulgadas; 4 . Por personas físicas para su uso privado; 5 . Acceso legal y fuente lícita; 6. Prohibición de utilización colectiva o lucrativa; 7. Las exclusiones del artículo 31.3; 8. Últimas modificaciones; V. CONCLUSIONES; VI. BIBLIOGRAFÍA.

* http://doi.org/10.15366/rjuam2019.39.003

Fecha de recepción: 31 de enero de 2019.

Fecha de aceptación: 21 de junio de 2019.

** Estudiante del Máster de Acceso a la Abogacía en la UAM y del Máster de Propiedad Intelectual, Industrial y Nuevas Tecnologías en la UAM. Este trabajo es una adaptación de mi Trabajo de Fin de Grado presentado en junio de 2018 y tutorizado por la profesora Pilar Cámara Águila. 


\section{INTRODUCCIÓN}

Entre los derechos atribuidos a los autores en el Real Decreto Legislativo 1/1996, de 12 de abril, por el que se aprueba el texto refundido de la Ley de Propiedad Intelectual (TRLPI en adelante); se encuentra el derecho de reproducción. Este derecho consiste, someramente, en la fijación de la obra en un soporte, es decir, la producción de ejemplares, de copias ${ }^{1}$. En el artículo 31.2 se establece un límite a este derecho, se denomina de copia privada. Gracias a él las personas físicas no requerirán de autorización del autor para realizar reproducciones para uso privado en cualquier soporte cuando concurran determinadas circunstancias. Es un límite tan solo aplicable al derecho de reproducción. Cualquier copia de una obra protegida que no vaya a ser usada dentro del ámbito privado personal y familiar necesitará de la autorización del autor².

Este límite cuenta con un alto grado de aceptación en los países de nuestro entorno jurídico. El texto más importante y de referencia en el ámbito internacional para el legislador español es la Directiva 2001/29/CE relativa a la armonización de determinados aspectos de los derechos de autor y derechos afines a los derechos de autor en la sociedad de la información. La mencionada Directiva tiene como base el artículo 17.2 de la Carta de Derechos Fundamentales de la Unión Europea que establece: «Se protege la propiedad intelectual». Para todos los Estados Miembros de la Unión Europea es obligatoria la transposición de esta directiva aprobada por el Parlamento Europeo y el Consejo a sus ordenamientos jurídicos internos, por lo que es aplicable en toda la Unión Europea.

A pesar de ser una norma destinada a armonizar las legislaciones internas de cada Estado Miembro, el límite de copia privada, incluido en el artículo 5.2 b), es facultativo ${ }^{3}$. Esto quiere decir que los Estados Miembros tienen la posibilidad de incluir el límite de copia privada en sus ordenamientos y pueden hacerlo o no. En cualquier caso, la Directiva establece imperativamente que si se optase por establecer este límite será obligatoria la creación de un sistema de compensación equitativa a los autores. Así, el límite de copia privada rompe con la finalidad armonizadora de la mencionada Directiva 2001/29 debido a su carácter voluntario. La copia privada está sujeta al arbitrio de los Estados Miembros y puede suceder que se den soluciones contradictorias en los distintos Estados Miembros ${ }^{4}$. Como ejemplos nos encontramos por un lado al Reino Unido que ha mantenido su tradición jurídica de no permitir como regla general la copia privada, Irlanda, que reconoce el límite de copia privada, sin embargo no ha establecido un sistema de compensación equitativa, o, por

1 BERCOVITZ ÁlVAREZ, G., en BERCOVITZ RODRÍGUEZ-CANO, R., Manual de propiedad intelectual, 6. ${ }^{\text {a }}$ ed., Valencia (Tirant lo Blanch), 2015, p. 82.

2 BERCOVITZ ÁlVAREZ, G., en BERCOVITZ RODRÍGUEZ-CANO, R., Manual de propiedad intelectual, ob. cit., p. 102.

3 Como nos recuerda GARROTE FERNÁNDEZ-DÍEZ, I., en BERCOVITZ RODRÍGUEZ-CANO,

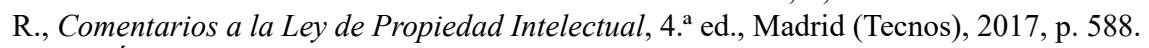

4 LÓPEZ MAZA, S., Limites del derecho de reproducción en el entorno digital, Granada (Comares), 2009, p. 172. 
otro lado, a España, Alemania ${ }^{5}$, Francia ${ }^{6}$, así como la mayoría de Estados Miembros, que no solo reconocen este límite sino que además tienen establecido un sistema de compensación equitativa por copia privada con un método de recaudación y reparto ${ }^{7}$.

Es importante señalar que muchos de los conceptos contenidos en el artículo 5.2 b) de la Directiva 2001/29, como "copia privada», "uso privado», "fines directa o indirectamente comerciales» o «compensación equitativa» son conceptos autónomos de derecho de la unión, y, por tanto, deben ser interpretados de manera uniforme en todos los Estados Miembros $^{8}$.

Desde su creación la Unión Europea se ha encargado y ha tratado de crear un sistema de copia privada fuerte en los Estados Miembros, sea a través de la jurisprudencia del Tribunal de Justicia de la Unión Europea, sea a través de otro tipo de actuaciones dirigidas a mejorar la armonización de la aplicación del artículo 5.2 b) de la Directiva 2001/29. Por ejemplo, en 2011 la Comisión Europea adoptó una estrategia para mejorar sus actuaciones en materia de propiedad intelectual e industrial en el período comprendido entre 2011 y 2014. La estrategia, titulada «Un mercado común para los derechos de propiedad intelectual», preveía en materia de copia privada la creación de una suerte de mediador para que actúe entre las distintas partes involucradas en este límite. Las competencias atribuidas a este mediador buscan eliminar los obstáculos que impiden una armonización eficiente de la copia privada, lo cual lleva a un mejor funcionamiento del mercado interior europeo. También aparece en la estrategia la intención de regular a nivel europeo los medios de copia y soportes que llevarán aparejado el pago de la compensación equitativa. Todo esto es parte de la reflexión que se producía en el seno de la Unión Europea sobre si hacer obligatorios o no los límites contemplados en la Directiva 2001/299.

El límite de copia privada también se incluye en diversos tratados internacionales sobre la protección de la propiedad intelectual. De hecho, aparece por primera vez en el artículo 9.2 del Convenio de Berna para la protección de obras literarias y artísticas, firmado en 1886. También aparece en el artículo 13 del Acuerdo sobre los aspectos de los derechos de propiedad intelectual relacionados con el comercio de 1994 (ADPIC en adelante) aprobado por la Organización Mundial del Comercio. Desde entonces los distintos Estados, no solo los europeos, lo han ido incluyendo en sus propios ordenamientos jurídicos internos.

\footnotetext{
$5 \quad$ Artículo 53 de la Gesetz über Urheberrecht und verwandte Schutzrechte (Urheberrechtsgesetz) (Ley de derecho de autor y derechos conexos, modificada hasta la Ley de 1 de septiembre de 2017). Fuente: Dejure. org.

6 Artículos L. 122-5 2 y L. 211-3 del Code de la propriété intellectuelle (Código de Propiedad Intelectual). Fuente: Legifrance.

7 Fuente: CISAC. Private Copying Global Study, (2017).

8 Apartado 37 de la Sentencia Padawan o apartado 35 de la Sentencia Reprobel.

9 GOTZEN, F. y MINERO ALEJANDRE, G., "Comentario a la estrategia de la Comisión Europea para 2011-2014 en materia de propiedad intelectual, "Un mercado común para los derechos de propiedad intelectual"», Pe. i.: Revista de Propiedad Intelectual, núm. 38, 2011, p.131.
} 
A nivel nacional, el límite de copia privada no se incluirá en el ordenamiento jurídico hasta que ya en plena democracia la Ley 22/1987, del 11 de noviembre, de Propiedad Intelectual, sustituyó a la primera ley en esta materia, la Ley de Propiedad Intelectual del 10 de enero 1879. Desde su creación este límite se mantiene con numerosas modificaciones hasta nuestros días.

\section{NATURALEZA Y JUSTIFICACIÓN}

Existe una discusión doctrinal acerca de la naturaleza del artículo 31.2 del TRLPI. No queda claro si lo que en él se consagra es un derecho del usuario, un límite al derecho de reproducción o más bien una excepción al mismo. Claramente no puede ser un derecho del usuario, puesto que, según la Constitución, la propiedad, y por ende la propiedad intelectual, no puede tener más límites que los impuestos por la ley ${ }^{10}$. En el Título III del TRLPI la copia privada es definida como un límite y así lo hace la mayoría de la doctrina. Sin embargo, lo más correcto sería tratar a la copia privada como excepción, puesto que este concepto encaja más con el funcionamiento efectivo que tiene. Los autores tienen siempre derecho a la explotación económica de su obra y solo en los casos establecidos en la ley y debidamente justificados en ella se podrá prescindir de la necesaria autorización ${ }^{11}$. Esto significa que la manera de funcionar de la copia privada es más bien el de una excepción. De cualquier manera, como se ha establecido anteriormente, la ley lo define como un límite y no como una excepción.

Al ser un límite y no un derecho del usuario, su construcción y su aplicación deben estar siempre de acuerdo con la llamada «regla de los tres pasos», de la que se hablará posteriormente. Adicionalmente, como consecuencia de su naturaleza de límite, el artículo 31.2 TRLPI debe ser interpretado de manera restrictiva ${ }^{12}$. La mayoría de la doctrina entiende que la copia privada cumple con la regla de los tres pasos. Se argumenta que, si existe un sistema de compensación equitativo, este límite no entra en conflicto con la explotación normal de la obra ni causa perjuicios injustificados ${ }^{13}$.

Hay numerosas razones que han llevado al legislador español y al europeo a permitir que las personas físicas puedan realizar copias de obras literarias, artísticas o científicas. La mayor y principal es la extraordinaria evolución de la tecnología de la información en las últimas décadas que han permitido: primero, un acceso generalizado, fácil, rápido y barato a aparatos y programas que permiten realizar copias (fotocopiadoras, impresoras, programas de copia de elementos audiovisuales, etc.), como a soportes donde realizar esas copias

\footnotetext{
10 Artículo 33.1 de la Constitución Española de 1978.

11 GARROTE FERNÁNDEZ-DÍEZ, I., en BERCOVITZ RODRÍGUEZ-CANO, R., Comentarios a la Ley de Propiedad Intelectual, 4. ${ }^{\mathrm{a}}$ ed., ob. cit., p. 590.

12 Así nos lo recuerda MARTÍN-PRAT, M., en XALABARDER, R., MARTÍN-PRAT, M., MALMIERCA, M. y RAMÍREZ, J., «La copia privada digital», Revista de Internet, Derecho y Política, núm. 1, 2005, p. 41.

13 LÓPEZ MAZA, S., Límites del derecho de reproducción en el entorno digital, ob. cit., p. 240.
} 
(sistemas de almacenamiento USB, tarjetas de memoria, ordenadores, teléfonos móviles, etc. $)^{14}$; segundo, la posibilidad de realizar un mayor número de copias con un gasto menor, en menos tiempo, y de mayor calidad ${ }^{15}$; y, por último, la posibilidad, cada vez más fácil de que las copias se hagan en un ambiente privado y doméstico. Por consecuencia de lo anterior, llevar un control del límite de copia privada sin incidir en el derecho a la intimidad personal y familiar o a la inviolabilidad del domicilio ${ }^{16}$. No obstante, la evolución tecnológica también permite, aunque en menor medida, mecanismos de control para la realización de esas copias, las medidas tecnológicas anticopia ${ }^{17}$. Sin embargo, los autores suelen ser reacios a instalar este tipo de medidas en sus obras ya que, esto, de acuerdo con la legislación vigente, supone que recibirán menos cantidad en concepto de compensación equitativa. Pero, a pesar de recibir una menor cantidad, el establecimiento de medidas tecnológicas no desplaza la obligación de pago de la compensación equitativa que tienen los deudores de la misma ${ }^{18}$. Tampoco desplaza esta obligación una eventual autorización del titular de derechos para realizar una copia de su obra ${ }^{19}$.

A título aclaratorio, es necesario distinguir la copia privada de la piratería puesto que son conceptos que suelen ser confundidos, si bien es cierto que ambos son facilitados y encubiertos por las nuevas tecnologías. Siempre que se hable de la incidencia en la propiedad intelectual de los avances tecnológicos hay que distinguir la copia privada, que es un límite legal al derecho de reproducción, de la piratería, que es, según la RAE, «robo, presa o destrucción de los bienes de otro». Por tanto, la piratería es un acto ilícito y tipificado en el Código Penal en sus artículos 270-272. En conclusión, las nuevas tecnologías facilitan un mayor y mejor uso del límite de copia privada, por esta razón el legislador decide incluirlo en el catálogo de límites a los derechos de explotación, sin embargo, también dan lugar a la aparición de nuevas formas de fraude a la propiedad intelectual más sutiles y menos detectables.

Otra de las razones que impulsan al legislador a permitir y regular la copia privada dentro de su ordenamiento de propiedad intelectual es la gran repercusión económica que el establecimiento de este límite tiene sobre los titulares de los derechos de propiedad intelectual. Efectivamente, la posibilidad de que los particulares puedan realizar copias sobre obras de las que dimanan una serie de derechos patrimoniales resultará en un perjuicio grave a los derechohabientes. Según Casas Vallés sobre el daño que se causa a los titulares de derechos por la copia privada: «no es un daño injustamente causado-ya que deriva de un acto

14 LÓPEZ MAZA, S., Límites del derecho de reproducción en el entorno digital, ob. cit., p. 175.

15 GONZÁLEZ GARCÍA, A., «La compensación equitativa por copia privada digital», Actualidad Jurídica Uría Menéndez, núm. 15, 2006, p. 2 de la versión electrónica.

16 LÓPEZ MAZA, S., Límites del derecho de reproducción en el entorno digital, ob. cit., p. 175.

17 GONZÁLEZ GARCÍA, A., «La compensación equitativa por copia privada digital», ob. cit., p. 2 de la versión electrónica.

18 Curia: STJUE del 27 de junio de 2013, VG Wort y otros, C-457/11-C460/11, EU:C:2013:426, apartado 59.

19 Curia: STJUE del 27 de junio de 2013, VG Wort y otros, C-457/11-C460/11, EU:C:2013:426, apartado 40. 
lícito- pero sí injustamente padecido ${ }^{20} »$. Para evitarlo, tanto el Convenio de Berna como el ADPIC señalan que se podrá establecer un límite de copia privada siempre y cuando «no atente a la explotación normal de la obra ni cause un perjuicio injustificado a los intereses legítimos del autor ${ }^{21} \gg$. La Directiva 2001/29 toma el testigo de los convenios anteriormente mencionados y en su artículo 5.2 b) consagra la obligatoriedad de una compensación equitativa cuando se establezca el límite. Además, en el artículo 5.5 se crea la mencionada "regla de los tres pasos". En virtud de esta regla un límite a los derechos de propiedad intelectual será lícito "si no entra en conflicto con la explotación normal de la obra o prestación y no perjudiquen injustificadamente los intereses legitimos del titular del derecho ${ }^{22} \gg$. Es decir, un límite debe ser: en primer lugar para casos concretos y tasados, en segundo lugar, no debe entrar en conflicto con la explotación normal de la obra y, en tercer lugar, no debe causar un perjuicio a los intereses de los derechohabientes. El legislador español en el artículo 40 Bis TRLPI también recoge la regla de los tres pasos. Este precepto "garantiza el carácter excepcional de las limitaciones, la explotación normal de la obra o prestación protegida por su titular, así como los legítimos intereses de este» ${ }^{23}$. La mayoría de la doctrina entiende que la copia privada cumple con la regla de los tres pasos siempre y cuando exista un sistema de compensación equitativo. En tal caso el límite no entrará en conflicto con la explotación normal de la obra ni causa perjuicios injustificados a los autores ${ }^{24}$.

El límite de copia privada lleva funcionando en nuestro país desde 1987 y desde entonces la doctrina también ha recogido una serie de argumentos que justifican la existencia de este límite y su sistema de compensación. El primero consiste en que al tratarse de actos de copia que se llevan a cabo en el ámbito privado resultaría de gran dificultad para los titulares de derechos y las entidades de gestión controlar el cumplimiento de una prohibición de copia, así como otorgar y gestionar posibles licencias. Tampoco sería fácil controlar el cumplimiento de las licencias. Así, los costes de gestión serían mayores que los ingresos, lo que convierte a una posible prohibición de copia en un ilícito imposible de controlar o garantizarse. En segundo lugar, siguiendo el camino establecido por el Convenio de Berna y el ADPIC, el límite de copia privada no afectará a los intereses de los derechohabientes ni a la explotación regular de la obra si se establece una adecuada compensación mediante un sistema idóneo. Por lo tanto, el límite de copia privada es perfectamente compatible con los derechos de los autores y demás sujetos protegidos. Por otro lado, se justifica también la existencia del límite de copia privada con los derechos de propiedad que tienen los legí-

20 CASAS VALLÉS, R., «La fotocopia y su régimen jurídico», Aranzadi Civil, núm. 1, 1993.

21 Tenor de ambos tratados, del artículo 9.2 del Convenio de Berna y del artículo 13 del ADPIC.

22 Tenor del propio artículo 5.5 de la Directiva 2001/29.

23 BERCOVITZ RODRÍGUEZ-CANO, R., «Las limitaciones y excepciones a los derechos de propiedad intelectual y el equilibrio entre los intereses afectados en el Derecho español», Pe. i.: Revista de Propiedad Intelectual, núm. extra 1, 2011, p. 14.

24 LÓPEZ MAZA, S., Límites del derecho de reproducción en el entorno digital, ob. cit., p. 240. 
timos adquirentes de soportes y medios de copia. Estos tienen derecho a maximizar el uso de esos aparatos y soportes que han adquirido legalmente cuyo uso idóneo es la copia ${ }^{25}$.

Finalmente, se incluyen como argumentos a favor de la copia privada una serie de razones que tienen más que ver con el interés público. Se habla del potencial que la copia privada tiene para acercar el conocimiento, la cultura, las ciencias y las artes a los particulares. Dicho de otra manera, se justifica la existencia del límite de copia privada con el derecho de los ciudadanos de acceso a la cultura, establecido en el artículo 44.1 de la Constitución. Este precepto reza: «Los poderes públicos promoverán y tutelarán el acceso a la cultura, a la que todos tienen derecho». Todo esto parece confirmar que una de las finalidades de este límite es la promoción de la ciencia, la investigación y el estudio. Como dice el profesor López Maza: «El interés público ha sido siempre una razón para justificar el derecho de autor, pero también para limitarlo ${ }^{26} \gg$.

\section{EVOLUCIÓN HISTÓRICA DEL LÍMITE DE COPIA PRIVADA Y SU SISTEMA DE COMPENSACIÓN}

En este apartado solo serán tratados con profundidad los aspectos de la copia privada que han sido eliminados a lo largo de su desarrollo. Aquellos cambios que se mantienen hasta nuestros días serán desarrollados con mayor detenimiento en el apartado IV.

Desde que se instauró en la legislación española el límite de copia privada, este ha sido objeto de fuertes críticas y controversias por parte de todos los sectores afectados. Este es el límite con mayor repercusión económica, inadmisible sin un sistema de compensación ${ }^{27}$. Según el profesor Bercovitz: "Se trata del límite en el que aflora de manera más fuerte la tensión entre el respeto a la propiedad intelectual y el derecho de información y acceso a la cultura ${ }^{28} \gg$. En la construcción del límite de copia privada se pretende encontrar un punto común donde se salvaguarden: la posibilidad de que los consumidores puedan realizar copias de obras protegidas para un uso privado, así como los intereses y derechos de los autores de dichas obras y de los fabricantes de medios de copia y soportes ${ }^{29}$. Por otro lado, el legislador español está obligado a garantizar este límite de acuerdo con la regulación que su homónimo europeo hizo en la Directiva 2001/29. En conclusión, el legislador se

25 Todos los argumentos recogidos en este párrafo han sido expuestos por GARROTE FERNÁNDEZDÍEZ, I., en BERCOVITZ RODRÍGUEZ-CANO, R., Comentarios a la Ley de Propiedad Intelectual, 4. ${ }^{\mathrm{a}}$ ed., ob. cit., pp. 589-590.

26 LÓPEZ MAZA, S., Limites del derecho de reproducción en el entorno digital, ob. cit., p. 175.

27 GARROTE FERNÁNDEZ-DÍEZ, I., en BERCOVITZ RODRÍGUEZ-CANO, R., Comentarios a la Ley de Propiedad Intelectual, 4. ${ }^{\mathrm{a}}$ ed., ob. cit., p. 589.

28 BERCOVITZ RODRÍGUEZ-CANO, R., «Las limitaciones y excepciones a los derechos de propiedad intelectual y el equilibrio entre los intereses afectados en el Derecho español», ob. cit., p. 15.

${ }^{29}$ GARROTE FERNÁNDEZ-DÍEZ, I. en BERCOVITZ RODRÍGUEZ-CANO, R., GARROTE FERNÁNDEZ-DÍEZ, I., GONZÁLEZ GONZALO, A. y SÁNCHEZ ARISTI, R., Las reformas de la ley de propiedad intelectual, Valencia (Tirant Lo Blanch), 2006, pp. 127-128. 
encuentra con una sociedad que avanza a pasos de gigante en tecnologías de la información y comunicación y a la vez se encuentra con una multiplicidad de derechos e intereses en juego y con la obligación de cumplir las directrices de la Unión Europea. Por tanto, el legislador se ha visto en numerosas ocasiones a delimitar con precisión el límite de copia privada, a adaptarlo y a cambiar su sistema de compensación siempre cumpliendo con la Directiva 2001/29. Debido a todas estas dificultades y exigencias la regulación del límite de copia privada y su sistema de compensación han sufrido numerosos cambios desde su instauración.

\section{1987-2006}

El período entre 1987 y 2006 es un período que podríamos denominar como preeuropeo en lo que concierne a la regulación de la propiedad intelectual. Comprende desde la aprobación de una moderna regulación de la propiedad intelectual en 1987 hasta que las Cortes aprueban la Ley 23/2006, de 7 de julio, por la que se modifica el texto refundido de la Ley de Propiedad Intelectual. Esta norma es la que se encarga de transponer la Directiva 2001/29 encargada de la armonización de la Propiedad Intelectual en la Unión Europea.

La antigua Ley de Propiedad Intelectual del 10 de enero de 1879, fue sustituida por la mencionada Ley 22/1987. Muchas son las razones que llevan al legislador a derogar la ley decimonónica, la principal de ellas es el desfase de la citada ley y su incapacidad para hacer frente a los cambios que se han producido en la sociedad española, una sociedad en la que, a diferencia de lo que ocurría en el Siglo XIX, la mayoría de los ciudadanos ya tiene acceso a la cultura. Se añade que el desarrollo cultural y tecnológico permitió a la vez la aparición de «nuevas modalidades de defraudación de los derechos de propiedad intelectual $^{30}{ }_{\text {}}$. Además, resulta especialmente preocupante para el legislador la necesidad de cumplir los convenios internacionales de los que España es parte, puesto que a lo largo del tiempo no se había modificado la Ley de Propiedad Intelectual de manera sustancial. En 1987 existía una grave necesidad de ponerse al día con las reformas llevadas a cabo en los países de nuestro entorno jurídico, especialmente las acaecidas en el seno de la Comunidad Europea $^{31}$. Más tarde, en 1996 se decidió hacer una legislación única de la propiedad intelectual y se sustituyó la Ley 22/1987 por el mencionado Real Decreto Legislativo 1/1996, el TRLPI, actualmente vigente.

La redacción que en la ley 22/1987 el legislador otorga al artículo 31. 2. ${ }^{\circ}$, encargado de regular la copia privada, es bastante primigenia, simplemente se limita a recoger los elementos esenciales del límite. Se entiende por elementos esenciales aquellas características que le dan entidad, es decir, aquellas propiedades sin las cuales no lo identificaríamos como tal.

\footnotetext{
30 Tal como se dice en el párrafo 2. ${ }^{\circ}$ del Preámbulo de la ley 22/1987, del 11 de noviembre, de Propiedad Intelectual.

31 Todas las razones expuestas aparecen en el preámbulo de la mencionada ley.
} 
Tres son las características más esenciales del límite de copia privada que quedan así recogidos por la Ley 22/1987: «Las obras ya divulgadas podrán reproducirse sin autorización del autor en los siguientes casos: $2{ }^{\circ}$ Para uso privado del copista y siempre que la copia no sea objeto de utilización colectiva ni lucrativa». De esta manera se organiza el límite de copia privada de forma general, sin una delimitación profunda. En esta regulación existe un elemento especialmente problemático a la hora de interpretarlo, el vocablo «copista». Este es un término abierto a amplias interpretaciones y fue objeto de polémica entre la doctrina. Esta palabra fue causante de un gran problema de seguridad jurídica debido a que no era capaz de delimitar con exactitud quién iba a estar incluido dentro del límite y quién no. El término «copista» puede englobar no solo a las personas físicas, también podría incluir a las personas jurídicas y a las entidades de derecho público. Sin embargo, la propia doctrina al final acordó que en el sentido de la ley «copista» no incluye a las personas jurídicas ${ }^{32}$.

La Ley 22/1987 en su artículo 25 estableció el sistema de compensación, este era el sistema conocido como canon de copia privada. Consistía en aparejar una cantidad pecuniaria en concepto de compensación equitativa a los aparatos susceptibles de realizar copias y los soportes. La doctrina definió esta compensación como una obligación resarcitoria pecuniaria ex lege $e^{33}$ y, además, tal como se establece en el artículo 25.9 es de gestión colectiva obligatoria a través de las entidades de gestión. Ahora bien, cada Estado Miembro es libre de decidir qué sistema de compensación equitativa por copia privada implanta y, sobre todo, es libre de desarrollarlo y de elegir el modo en que se garantice que los autores realmente perciben esa compensación ${ }^{34}$.

Es especialmente relevante en el desarrollo de las condiciones necesarias para que haya copia privada el Real Decreto 1434/1992, de 27 de noviembre, de desarrollo de los artículos 24, 25 y 140 de la Ley 22/1987, de 11 de noviembre, de Propiedad Intelectual, en la versión dada a los mismos por la Ley 20/1992, de 7 de julio. Por ejemplo, el artículo 9 de esta norma delimita una serie de conceptos que se incluyen dentro de la compensación equitativa por copia privada, así como otras figuras que excluye, como a los programas de ordenador.

Por otro lado, en lo que respecta a las condiciones de copia privada resulta especialmente relevante el artículo 10. En él se dice expresamente: «no tienen la consideración de reproducciones para uso privado del copista, en el sentido del apartado 2 del artículo 31 de la Ley de Propiedad Intelectual: a) Las efectuadas en establecimientos dedicados a la realización de reproducciones para el público, o que tengan a disposición del público los equipos, aparatos y materiales para su realización». Este precepto ya adelanta una de las

32 GARROTE FERNÁNDEZ-DÍEZ, I., en BERCOVITZ RODRÍGUEZ-CANO, R., Comentarios a la ley de propiedad intelectual, 3. ${ }^{\mathrm{a}}$ ed., Madrid (Tecnos), 2007, p. 559.

33 GARROTE FERNÁNDEZ-DÍEZ, I., en BERCOVITZ RODRÍGUEZ-CANO, R., Comentarios a la Ley de Propiedad Intelectual, 4. ${ }^{\text {a }}$ ed., ob. cit., p. 520.

${ }_{34}$ Curia: STJUE del 16 de junio de 2011, Stichting de Thuiskopie, C-462/09, EU:C:2011:397, apartado 41. 
condiciones que se incluirán en 2014: la asistencia de terceros. Además de esto, el Real Decreto 1434/1992 unifica y guía la interpretación consolidada del artículo $31.2^{35}$.

Como se ha señalado anteriormente, en 2001 la Unión Europea decidió armonizar el derecho interno de los Estados Miembros en materia de propiedad intelectual, a tal efecto se aprobó la Directiva 2001/29. Esta armonización comportó una profunda remodelación del sistema de copia privada en España.

\section{2006-2011 y el caso Padawan}

Cinco años después de la aprobación de la Directiva 2001/29, las Cortes aprueban la mencionada Ley 23/2006 dirigida a adaptar el TRLPI a las nuevas exigencias de la Unión Europea. Además de eso, esta norma trata de resolver problemas interpretativos que se habían dado tras años de experiencia con el funcionamiento de la copia privada.

La primera modificación importante que hace la Ley 23/2006 es sustituir el término «copista» por «persona fisica». De este modo, el legislador pretende zanjar de una vez la discusión sobre quién puede ser beneficiario de este límite. Se excluye de la posibilidad de crear copias privadas a toda clase de persona jurídica, empresa o entidad pública ${ }^{36}$. Tampoco estarán amparadas por el artículo 31.2 las copias de cualquier tipo de obra que los miembros del personal de una empresa o entidad pública hagan en su propio beneficio usando los materiales puestos a su disposición por las mismas ${ }^{37}$. Así pues, bajo ninguna circunstancia una persona jurídica podría ser beneficiaria del límite de copia privada y por tanto no está obligada a pagar el canon de compensación equitativa.

La sustitución del término «copista» por "persona física» también trajo como consecuencia la derogación parcial del artículo 10 del mencionado RD 1434/1992 donde se excluía de la copia privada a las copias realizadas en aparatos ajenos ${ }^{38}$. Por otro lado, sí serán consideradas copias privadas aquellas reproducciones que los particulares hagan en establecimientos abiertos al público, pero sin asistencia, ellos solos. De este modo se incluyen las copias hechas en copisterías si no son realizadas por el personal, es decir, si solo se ponen a disposición del cliente los aparatos y el personal se limita a cobrar a los clientes ${ }^{39}$.

35 MARTÍN SALAMANCA, S., en RODRÍGUEZ TAPIA, J. M., Comentarios a la ley de propiedad

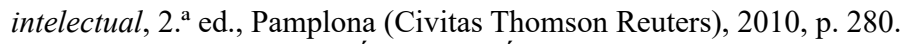

36 GARROTE FERNÁNDEZ-DÍEZ, I. en BERCOVITZ RODRÍGUEZ-CANO, R., GARROTE FERNÁNDEZ-DÍEZ, I., GONZÁLEZ GONZALO, A. y SÁNCHEZ ARISTI, R., Las reformas de la ley de propiedad intelectual, ob. cit., p. 45.

37 GONZÁLEZ GARCÍA, A., «La compensación equitativa por copia privada digital», ob. cit., p. 5 de la versión electrónica.

38 GARROTE FERNÁNDEZ-DÍEZ, I., en BERCOVITZ RODRÍGUEZ-CANO, R., Comentarios a la ley de propiedad intelectual, 3 . $^{\mathrm{a}}$ ed., ob. cit., p. 560.

39 GARROTE FERNÁNDEZ-DÍEZ, I., en BERCOVITZ RODRÍGUEZ-CANO, R., GARROTE FERNÁNDEZ-DÍEZ, I., GONZÁLEZ GONZALO, A. y SÁNCHEZ ARISTI, R., Las reformas de la ley de propiedad intelectual, ob. cit., p. 46. 
La Ley 23/2006 también añade que solo se incluirán dentro del ámbito de aplicación del artículo 31.2 las reproducciones de «obras a las que haya accedido legalmente», esta es una medida no contenida en la normativa europea y es especialmente útil en los casos de obras obtenidas en redes P2P o incluso en puestos callejeros (top manta $)^{40}$. Lo anterior se debe interpretar en sentido estricto, por tanto, este requisito solo se refiere al acceso, todavía no se refiere a que la obra copiada sea un ejemplar lícito ${ }^{41}$. Se tiene en cuenta un carácter subjetivo, la buena fe, es decir, si la ignorancia del beneficiario del límite la ilicitud del ejemplar que copia. Esta circunstancia es relevante a la hora de calificar la reproducción como amparada por el artículo $31.2 \mathrm{o} \mathrm{no}^{42}$.

Por otro lado, siguiendo la estela de la Directiva 2001/29 la Ley 23/2006 establece que el límite de copia privada se aplica a las reproducciones hechas «en cualquier soporte». Así se pretende despejar dudas sobre si el límite es aplicable a las reproducciones hechas en soportes digitales. Podría llegarse a esta conclusión siguiendo el espíritu y finalidad de la norma europea cuyo objetivo es adaptar la regulación de la propiedad intelectual a la sociedad de la información ${ }^{43}$. De este modo se aclara que el límite se aplica tanto a soportes analógicos como digitales. No importa si el soporte es tangible o no ${ }^{44}$. Ambos soportes, analógicos y digitales están sujetos al pago de la compensación equitativa (por eso desde entonces se habla de canon de copia privada digital). La Directiva y por tanto la mencionada ley de transposición también establecen que se deberá tener en cuenta si se aplican medidas de protección, esto es, medidas anticopia. Según Agustín González es muy importante atender a estas medidas puesto que: "[...] podría suceder que el usuario pagara dos veces por el mismo derecho de reproducción (una en concepto de precio del producto o de la licencia y un segundo pago por el canon de copia privada) o que pague un canon para hacer copias que la tecnología le impide obtener ${ }^{45} \gg$.

En 2010 la Audiencia Provincial de Barcelona en el caso de SGAE c. Padawan interpuso una serie de cuestiones prejudiciales ante el TJUE en relación con la conformidad del sistema de compensación equitativa español (concretamente habla de la Orden PRE1743/2008) con el derecho europeo. Es importante remarcar que el criterio que se usaba en España para gravar los soportes y aparatos es el de idoneidad, este es un criterio de daño potencial a los autores ${ }^{46}$. El sistema español se fija en la posibilidad de que esos materiales

40 MARTÍN SALAMANCA, S., en RODRÍGUEZ TAPIA, J. M., Comentarios a la ley de propiedad intelectual, ob. cit., p. 281.

41 GARROTE FERNÁNDEZ-DÍEZ, I., en BERCOVITZ RODRÍGUEZ-CANO, R., GARROTE FERNÁNDEZ-DÍEZ, I., GONZÁLEZ GONZALO, A. y SÁNCHEZ ARISTI, R., Las reformas de la ley de propiedad intelectual, ob. cit., p. 135.

42 LÓPEZ MAZA, S., Límites del derecho de reproducción en el entorno digital, ob. cit., p. 221.

43 Considerandos 5 y 38 de la Directiva 2001/29.

44 LÓPEZ MAZA, S., Límites del derecho de reproducción en el entorno digital, ob. cit., p. 186.

45 GONZÁLEZ GARCÍA, A., «La compensación equitativa por copia privada digital», ob. cit., p. 7 de la versión electrónica.

46 Apartado tercero de JIMÉNEZ SERRANÍA, V., «La "sentencia sobre el canon”: vicios y virtudes del sistema de compensación de copia privada en España, comentario a la STJUE de 21 de octubre 2010, c- 467/08, caso padawan vs. SGAE», Revista General de Derecho Europeo, núm. 22, 2010. 
sean susceptibles de fijar o soportar copias independientemente de que vayan a tener ese uso, lo cual condujo a una aplicación del canon indiscriminada donde no se comprobaba la verdadera utilización de los materiales sujetos a esta compensación. El TJUE prohibió la aplicación indiscriminada del canon.

"[...] es necesaria una vinculación entre la aplicación del canon destinado a financiar la compensación equitativa en relación con los equipos, aparatos y soportes de reproducción digital y el presumible uso de éstos para realizar reproducciones privadas. En consecuencia, la aplicación indiscriminada del canon por copia privada, en particular en relación con equipos, aparatos y soportes de reproducción digital que no se hayan puesto a disposición de usuarios privados y que estén manifiestamente reservados a usos distintos a la realización de copias privadas, no resulta conforme con la Directiva 2001/2947》.

Aunque esta Sentencia no hablaba de las circunstancias en las que se puede dar la copia privada sino de su sistema de compensación, comportó un cambio de etapa en la construcción del límite. A partir de esta Sentencia se modificó el artículo 31.2 para reflejar en él lo que la Sentencia Padawan establece, tratando de hacer efectivo que solo las personas físicas se pueden beneficiar del límite de copia privada.

\section{2011-2017 y el caso EGEDA y otros}

Tras la publicación de la Sentencia Padawan, el legislador español a través de la Disposición Adicional Décima del Real Decreto-ley 20/2011, de 30 de diciembre, de medidas urgentes en materia presupuestaria, tributaria y financiera para la corrección del déficit público, en vez de simplemente mejorar el sistema del canon digital, decidió suprimirlo. Esta norma simplemente hizo efectiva su supresión, pero las leyes encargadas del desarrollo del sistema que sustituiría al canon digital fueron las siguientes: en primer lugar la Ley 21/2014, de 4 de noviembre, por la que se modifica el texto refundido de la Ley de Propiedad Intelectual, aprobado por Real Decreto Legislativo 1/1996, de 12 de abril, y la Ley 1/2000, de 7 de enero, de Enjuiciamiento Civil; y, en segundo lugar, el Real Decreto 1657/2012, de 7 de diciembre, por el que se regula el procedimiento de pago de la compensación equitativa por copia privada con cargo a los Presupuestos Generales del Estado.

La citada Ley 21/2014 se encargó de realizar una profunda remodelación del artículo 31.2 estableciendo nuevos requisitos para acceder al límite de copia privada reduciendo así su campo de aplicación ${ }^{48}$. El primero de ellos es el requisito de realizar la copia sin «asistencia de terceros», que se mantiene hasta nuestros días. El añadido más sorprendente de

47 Curia: STJUE del 21 de octubre de 2010, Padawan, C-467/08, EU:C:2010:620, apartado 59.

48 El Profesor BERCOVITZ RODRÍGUEZ-CANO, R., en VV. AA., La reforma de la Ley de Propiedad Intelectual, Valencia (Tirant lo Blanch), 2015, p. 73. Y en la propia Exposición de Motivos de la Ley 21/2014. 
todos ellos es el realizado sobre el requisito de acceso legal a la obra, en aquel momento se determinó que se tendría que hacer también «desde fuente lícita» y es la propia ley en el apartado b) del artículo 31.2 la que estableció cuáles son esos supuestos de acceso desde fuente lícita. Podían ser objeto de copia privada las obras en un soporte autorizado adquiridas "por compraventa mercantil» y aquellas obras a las que se accediese por un acto de comunicación pública (en el sentido del artículo 20 TRLPI) que no hubiesen sido hechas mediante fijación no autorizada en un espacio o establecimiento público. Llama mucho la atención la especificación de que la compraventa debía ser mercantil. Esto parece contradictorio con el propósito de la norma, puesto que las compraventas entre consumidor y comerciante y las compraventas entre particulares son compraventas civiles ${ }^{49}$. Podría pensarse que el legislador quería acotar la copia privada a las compraventas entre comerciantes, pero esto no puede ser dado que los empresarios no son beneficiarios del límite de copia privada. Todo parece apuntar a que había que hacer una interpretación correctora y considerar que el legislador se refería a compraventa en establecimiento mercantil ${ }^{50}$. Ya no se considerarían lícitas y, por tanto, se excluyeron de la compensación equitativa las copias realizadas a obras contenidas en soportes que no son propiedad del beneficiario del límite de copia privada, esto es, las alquiladas o prestadas; las no compradas en establecimiento mercantil, las realizadas sobre obras en soporte digital y, evidentemente, las realizadas sobre obras puestas a disposición de manera ilícita (piratería o top manta) ${ }^{51}$.

En el artículo 31.2 se realizaron otras pequeñas modificaciones sin una incidencia determinante y con el objetivo de reforzar la intención de la ley de acuerdo a la Sentencia Padawan ${ }^{52}$ y que devinieron redundantes. Un ejemplo de ello es: «c) Que la copia obtenida no sea objeto de una utilización colectiva ni lucrativa, ni de distribución mediante precio». Este añadido buscaba alinearse con el tenor del artículo 5.2 b) de la Directiva 2001/29 que no permite «un uso directa o indirectamente comercial», que, de hecho, ya se contiene en el apartado a) del artículo 31.2.

Por otro lado, el citado RDL 1657/2012 introdujo una forma radicalmente distinta de compensación equitativa por copia privada. Esta correría a cargo de los Presupuestos Generales del Estado (PPGGE en adelante). El nuevo sistema encontró un rechazo generalizado por parte de los acreedores del límite debido a que la recaudación en concepto de compensación por copia privada se redujo exorbitantemente.

49 El Profesor BERCOVITZ RODRÍGUEZ-CANO, R., en VV. AA., La reforma de la Ley de Propiedad Intelectual, ob. cit., pp. 75-76. A su vez se remite al artículo 326 del Código de Comercio.

50 MARTÍNEZ ESPÍN, P., en VV. AA., Estudios sobre la Ley de Propiedad Intelectual: últimas reformas y materias pendientes, Madrid (Dykinson), 2016, p. 459.

51 MARTÍNEZ ESPÍN, P., en VV. AA., Estudios sobre la Ley de Propiedad Intelectual: últimas reformas $y$ materias pendientes, ob. cit., p. 459.

52 GARROTE FERNÁNDEZ-DÍEZ, I., en BERCOVITZ RODRÍGUEZ-CANO, R., Comentarios a la Ley de Propiedad Intelectual, 4. ${ }^{\text {a }}$ ed., ob. cit., p. 593. 
¿Cuál podía ser la intención del legislador al realizar cambios tan profundos? En 2014, dos años después de imponer la compensación equitativa por copia privada a los PPGGE, cuando a través de la mencionada Ley $21 / 2014$ se redujo drásticamente la posibilidad de acceder a este límite, también se redujo cuantiosamente la cantidad destinada a esta compensación. El profesor Bercovitz indica que de 2011 donde la Orden PRE-1743/2008 preveía una recaudación de entre 110.200.000 y 117.800.000 euros, se pasó a una recaudación de 8.636.728,09 de euros para el año 2012 ${ }^{53}$. Resulta claro que la intención final del legislador era la de restringir las copias amparadas por el límite de copia privada. Cuantas menos copias se hiciesen bajo el paraguas del artículo 31.2, menos compensación habría que dar y, por tanto, la partida dedicada a ello sería más barata. Como conclusión, la intencionalidad del legislador al introducir estas modificaciones en el artículo 31.2 era doble: por un lado, restringir el ámbito de la copia privada y, por otro lado y como consecuencia, reducir drásticamente la cantidad a pagar en concepto de compensación equitativa con el consiguiente ahorro para las arcas públicas.

En cualquier caso, resulta muy chocante que el pago de la compensación se impusiese a todos los contribuyentes después de que el TJUE en el Caso Padawan declarase no conforme a derecho el sistema de compensación equitativa español por hacer soportar su pago también a quienes no iban a usar equipos o soportes para copia privada. Según Pascual Martínez: "[...] el pago con cargo a los PPGGE supone una desconexión total entre quienes realizan copias privadas (y por tanto causan el daño a los titulares de derechos) y quien está obligado a reparar el perjuicio ${ }^{54} \gg$.

El Tribunal Supremo durante el curso de un procedimiento entre una serie de entidades de gestión de derechos (EGEDA, DAMA y VEGAP) y la Administración del Estado planteó una serie de cuestiones prejudiciales al TJUE sobre la conformidad con el derecho europeo del nuevo sistema de compensación. La respuesta se dio con la Sentencia EGEDA y otros. En esta ocasión el TJUE rechazó la conformidad del sistema con cargo a los PPGGE por una razón parecida a la del caso Padawan, debido a que no se garantizaba que fuesen a ser los beneficiarios de las copias privadas los que soportasen la compensación y no se impusiese a sujetos que no fuesen manifiestamente a usar equipos y soportes para realizar copias privadas. La partida destinada a la compensación se sacaba del total de los PPGGE y no solo de impuestos que solo pagan las personas físicas, como el IRPF. Tal como dice la Sentencia del TJUE:

"[...] habida cuenta del hecho de que no existe afectación de ingresos concretos - como los procedentes de un tributo específico-a gastos determinados, ha de considerarse que la partida presupuestaria destinada al pago de la compensación

\footnotetext{
53 El Profesor BERCOVITZ RODRÍGUEZ-CANO, R., en VV. AA., La reforma de la Ley de Propiedad Intelectual, ob. cit., p. 66.

54 MARTÍNEZ ESPÍN, P., en VV. AA., Estudios sobre la Ley de Propiedad Intelectual: últimas reformas $y$ materias pendientes, ob. cit., p. 469.
} 
equitativa se alimenta de la totalidad de los recursos con los que cuentan los Presupuestos Generales del Estado, y, por tanto, del mismo modo, de todos los contribuyentes, incluidas las personas jurídicas. [...] no se desprende que, en el presente caso, exista mecanismo alguno que permita a las personas jurídica, [...] solicitar la exención de la obligación de contribuir a financiar esta compensación, o, al menos, solicitar la devolución de esta contribución $[\ldots]^{55} 》$.

La doctrina de esta Sentencia fue aplicada por el Tribunal Supremo en la Sentencia de la Sala Tercera del 10 de noviembre de $2016^{56}$ donde se anuló el sistema de compensación equitativo con cargo a los PPGGE.

De esta manera el legislador vio rechazada por la doctrina del TJUE el sistema de compensación equitativa por copia privada por la misma razón que en 2011. En consecuencia, se volvió a reformar el límite de copia privada.

\section{CONSTRUCCIÓN ACTUAL DEL LÍMITE DE COPIA PRIVADA}

Como se ha expuesto anteriormente, en 2016 el TJUE en la mencionada Sentencia EGEDA y otros, una vez más, declaró la no conformidad con el derecho europeo del sistema español de compensación equitativa por copia privada, por lo que el legislador tuvo que volver a reestructurar este límite. Siguiendo la línea de actuación que establecieron tras la publicación de la Sentencia Padawan, nuestro legislador volvió a cambiar completamente de rumbo. En vez de introducir enmiendas al sistema con cargo a los PPGGE para que la compensación la soportasen únicamente las personas físicas (a través del IRPF, por ejemplo); decide volver al sistema de canon digital que abandonó en 2011.

Para adaptar este sistema a las exigencias de la UE se aprobó el Real Decreto-Ley $12 / 2017$, de 3 de julio, por el que se modifica el texto refundido de la Ley de Propiedad Intelectual, aprobado por el Real Decreto Legislativo 1/1996, de 12 de abril, en cuanto al sistema de compensación equitativa por copia privada. Esta norma cambió radicalmente el artículo 25 sobre la compensación, pero respetó la estructura que la mencionada Ley 21/2014 había otorgado al artículo 31.2 modificando pequeños aspectos. El principal cambio en el sistema de compensación equitativa por copia privada que introdujo el RDL 12/2017 se da en el apartado 7 del artículo 25 donde se prevé que ciertas entidades y personas estén exceptuadas de la compensación equitativa por copia privada. Estas son: entidades del sector público, personas físicas o jurídicas actuando como consumidores finales que justifiquen un uso exclusivamente profesional, personas autorizadas por el autor para hacer la copia y turistas y viajeros que vayan a usar lo comprado fuera de España. Así el principio de idoneidad del que antes se hablaba cada vez es más relativo. En palabras del profesor

55 Curia STJUE del 9 de junio de 2016, EGEDA y otros, C-470/14, EU:C:2016:418, apartados 39 y 40.

56 CENDOJ: ROJ: STS 4832/2016. Sentencia del Tribunal Supremo 2394/2016 del 10 de noviembre de 2016. 
Rafael Sánchez Aristi: "El principio de “idoneidad” de los quipos, aparatos y soportes de reproducción, consagrado en el artículo 25.1 TRLPI y clave de bóveda del sistema de compensación equitativa, está sujeto a cada vez más excepciones y modulaciones ${ }^{57}$ 》. Esta es la manera en la que el legislador español pretende, finalmente, adaptar de la manera más correcta su sistema de compensación equitativa a las directrices europeas, que había sido siempre en lo que había fallado.

En cuanto al texto del propio artículo 31.2, el mencionado Real Decreto-ley 12/2017 solo cambió el requisito que habla sobre la forma de acceso a la obra. De modo que el legislador pretende hacer una mejor construcción del límite de copia privada y su sistema de compensación con el objetivo de dotarle de una vocación de continuidad y permanencia adaptándolo a derecho europeo y, así, lograr un sistema estable.

El límite de copia privada hoy en día se encuentra regulado en los apartados 2 y 3 del artículo 31 del TRLPI. En el artículo 31.2 se establecen los requisitos y condiciones que debe cumplir el acto de reproducción para ser considerado copia privada y por tanto estar exento de autorización del autor. En el artículo 31.3 se establece que los casos ahí enumerados no tendrán en ningún caso la consideración de copia privada. El artículo 31.2 lo primero que hace es definir el límite de copia privada. Son reproducciones que no necesitarán de la autorización del autor. Para que esto suceda se deben dar una serie de requisitos que, en todo caso, deben concurrir, según el propio artículo 31.2, «simultáneamente», es decir, se deben cumplir todos a la vez, no son requisitos alternativos, sino cumulativos ${ }^{58}$. Si se cumplen las reproducciones realizadas serán copias privadas lícitas y generarán una obligación de compensación. En caso de no reunir los requisitos legales la copia realizada no estará al amparo de este límite y necesitará autorización. Los requisitos son:

\section{Sobre cualquier soporte}

De entre todas las condiciones requeridas la primera que se menciona es aquella que se refiere al soporte. Se considerará copia privada cualquier reproducción hecha «en cualquier soporte». Esta condición es el resultado del traslado literal del contenido de la Directiva $2001 / 29$. Significa que el soporte en el que se realice la reproducción es indiferente a la hora de su consideración como copia privada. El ámbito de aplicación de este límite se extiende a las copias analógicas, las digitales ${ }^{59}$, las reprográficas, etc. A efectos de condición para que haya copia privada no se distingue entre copias analógicas o digitales. Sin embargo,

57 SÁNCHEZ ARISTI, R., «El renovado sistema de compensación equitativa por copia privada tras el Real Decreto-Ley 12/2017», La Ley mercantil, núm. 46, 2018, p. 14 de la versión electrónica.

58 GARROTE FERNÁNDEZ-DÍEZ, I., en BERCOVITZ RODRÍGUEZ-CANO, R., Comentarios a la Ley de Propiedad Intelectual, 4. ${ }^{\text {a }}$ ed., ob. cit., p. 591.

59 GARROTE FERNÁNDEZ-DÍEZ, I., en BERCOVITZ RODRÍGUEZ-CANO, R., GARROTE FERNÁNDEZ-DÍEZ, I., GONZÁLEZ GONZALO, A. y SÁNCHEZ ARISTI, R., Las reformas de la ley de propiedad intelectual, ob. cit., p. 129. 
debido al mayor impacto económico que tienen las copias digitales ${ }^{60}$, sí se distinguen a la hora de la cuantificación de la compensación equitativa ${ }^{61}$.

\section{Sin la asistencia de terceros}

Este es un requisito que no recoge la Directiva 2001/29, lo cual demuestra que el derecho europeo es menos restrictivo que el español en materia de copia privada, puesto que su ámbito es más amplio. Este requisito exige que la persona física que vaya a realizar la copia privada la haga solo, «sin asistencia de terceros». De entrada, se excluyen del ámbito de aplicación de este artículo las copias realizadas en establecimientos abiertos al público mediando precio y gracias a los suministros del establecimiento. De esta manera los dependientes de reprografías y copisterías no están habilitados a realizar copias de obras protegidas para el uso personal del cliente.

Presenta más dificultad la copia por encargo privada, es decir, la copia que una persona física hace a otra persona física y esta la realiza con sus propios medios, no en un establecimiento abierto al público y sin mediar precio. El profesor Bercovitz cree que la Directiva admite la copia por encargo ${ }^{62}$. «Es obvio que el requisito se refiere a la asistencia profesional o empresarial y no a la ayuda que cualquiera puede obtener de un particular que lo haga por razón de su relación personal con el beneficiario de la copia ${ }^{63} \gg$. Por otro lado, el TJUE en la Sentencia del 5 de marzo de 2015, Copydan Båndkopi declara la conformidad con derecho europeo de las copias por encargo privadas, y, por tanto, se considerarán copias privadas al amparo de este límite. "[...] la Directiva 2001/29 no se opone a una normativa nacional que establece una compensación equitativa por las reproducciones de obras protegidas efectuadas por una persona física a partir o mediante un dispositivo que pertenece a un tercero ${ }^{64} 》$. De esta manera, aunque la reproducción la realice un tercero, siempre y cuando se encuentre dentro del círculo personal y familiar del destinatario, si la realiza con sus propios equipos y no en un establecimiento abierto al público, estará amparada por el artículo 31.2 y no necesitará la autorización del autor. El elemento esencial es evitar la asistencia profesional de terceros ${ }^{65}$.

Resulta especialmente reseñable la Sentencia VCAST contra R.T.I. Su interés radica en que es una de las primeras sentencias en pronunciarse sobre la conformidad con la regu-

\footnotetext{
60 Considerando 38 de la Directiva 2001/29.

${ }_{61}$ LÓPEZ MAZA, S., Límites del derecho de reproducción en el entorno digital, ob. cit., p. 249.

62 BERCOVITZ RODRÍGUEZ-CANO, R., «Más sobre la copia privada. Revista Doctrinal», Aranzadi Civil-Mercantil, núm. 3, 2015, p. 1 de la versión electrónica.

63 El profesor BERCOVITZ RODRÍGUEZ-CANO, R., en VV. AA., La reforma de la Ley de Propiedad Intelectual, ob. cit., p. 73.

64 Curia: STJUE del 5 de marzo de 2015, Copydan Båndkopi, C-463/12, EU:C:2015:144, apartado 91.

65 GARROTE FERNÁNDEZ-DÍEZ, I., en BERCOVITZ RODRÍGUEZ-CANO, R., Comentarios a la Ley de Propiedad Intelectual, 4. a ed., ob. cit., p. 592.
} 
lación de la copia privada de una serie de servicios que hoy son más que cotidianos, en este caso el almacenamiento en la nube. VCAST es un proveedor británico de servicios nVPR ${ }^{66}$ que se dedica a grabar en las cuentas privadas del cliente en la nube (como en Dropbox o Google Drive) emisiones de canales de televisión como R.T.I., una empresa italiana, a petición del cliente. Lo particular de este caso es que, como dice la propia publicidad de VCAST, esta «interviene activamente en la grabación». No es el cliente el que graba sino VCAST, por tanto, a todas luces parece que hay asistencia de terceros. Lo que parece en un principio un acto de copia privada, resulta ser un acto de comunicación al público ${ }^{67}$. El TJUE observó que no hay un acto de copia privada sino de puesta a disposición del público dado que se dan los dos elementos de este acto: un acto de comunicación y un público que debe ser un público nuevo y además las obras protegidas se transmiten por medios de difusión distintos ${ }^{68}$. Un acto de comunicación es toda transmisión de las obras protegidas a un público sin entrega de un ejemplar de la obra en soporte físico. El público es un número indeterminado y considerable de destinatarios potenciales. Además, el público es nuevo, puesto que es un público que el autor no tuvo en cuenta cuando difundió la obra a través de R.T.I. En conclusión, no hay un acto de copia privada sino un acto de comunicación al público. En consecuencia, un servicio nVPR no puede ser considerado como copia privada ni puede acogerse en este límite ${ }^{69}$.

De este modo la actividad de VCAST es ilícita puesto que no pide la necesaria autorización del autor para grabar emisiones de televisión y luego ponerlas a disposición de sus usuarios en sus cuentas en la nube ${ }^{70}$. La copia privada nunca puede servir para facilitar vulneraciones de los derechos de autor o afines, es decir, nunca se puede utilizar este límite para expropiar al autor de otros derechos que tiene sobre su obra como el derecho patrimonial de comunicación pública ${ }^{71}$.

La resolución del TJUE «se alinea con la jurisprudencia alemana y francesa que se había pronunciado sobre los servicios $n V P R$ por cuanto concluye que deben ser autorizados por los titulares de derechos ${ }^{72} \gg$. Aunque se pudiese hablar de copia privada, la reproducción que hace en la nube VCAST no estaría amparada por el límite puesto que haría una

${ }_{66}$ Siglas en inglés de grabadora de vídeo personal en red.

67 BERCOVITZ RODRÍGUEZ-CANO, R., «Copias privadas en la nube y comunicación pública», Revista Doctrinal Aranzadi Civil-Mercantil, núm. 3, 2018, p. 1 de la versión electrónica.

68 Curia: STJUE del 29 de noviembre de 2017, VCAST, C-265/16, EU:C:2017:913. Apartados 41-50.

69 GÓNZALEZ SAQUERO, P., «Reseña de la Sentencia en el asunto C-265/16 VCAST Limited / RTI SpA (TJCE 2017, 218)», Revista Española de Derecho Europeo, núm. 65, 2018.

70 BERCOVITZ RODRÍGUEZ-CANO, R., «Copias privadas en la nube y comunicación pública», ob. cit., p. 1 de la versión electrónica.

71 BERCOVITZ RODRÍGUEZ-CANO, R., «Copias privadas en la nube y comunicación pública», ob. cit., p. 2 de la versión electrónica.

${ }_{72}$ MUÑOZ VICO, A., «¿Hacia una copia privada en la nube? Comentario a la sentencia del Tribunal de Justicia de la Unión europea de 29 de noviembre de 2017 en el asunto C-265/16», Pe. i.: Revista de Propiedad Intelectual, núm. 57, 2017, p. 69. 
reproducción ilícita dado que falta la preceptiva autorización del autor para hacer un acto de comunicación pública.

Esta Sentencia no es aplicable a todos los servicios de reproducción en la nube debido a este elemento diferencial de la participación activa del tercero profesional en la grabación. Así el Tribunal que interpone las cuestiones prejudiciales del caso desmarca VCAST de otros servicios en la nube como Dropbox o Google Drive ${ }^{73}$. Parece claro que servicios de reproducción y almacenamiento en la nube en los que no existe asistencia de terceros están en pleno acuerdo con la regulación de copia privada y, así, quedan amparados por ella ${ }^{74}$. De hecho, así se pronunció el Abogado General del caso, Maciej Szpunar: «Mientras sea el usuario quien tome la iniciativa de la reproducción y quien determine el objeto y las modalidades de la misma, no veo una diferencia decisiva entre ese acto y la reproducción realizada por el mismo usuario mediante equipos manejados directamente por él» ${ }^{75}$.

\section{De obras ya divulgadas}

El límite de copia privada solo ampara las copias «de obras ya divulgadas», se debe entender este término en el sentido que le da el artículo 4 TRLPI. Por tanto, solo son copias privadas aquellas que se hace de obras que ya se hayan hecho accesibles al público por primera vez. Este requisito refuerza el derecho moral de divulgación de los autores sobre sus obras establecido en el artículo 14.1 y por tanto una persona que realice copias amparadas por el artículo 31.2 no puede en ningún caso expropiar al autor de su derecho de divulgación ${ }^{76}$. También sirve para que el derechohabiente no pierda el control de sus obras no divulgadas ${ }^{77}$. Puede plantearse la duda si este requisito protege a una obra que no ha sido divulgada en España, pero sí en el extranjero. El profesor López Maza acude al derecho francés, concretamente a una sentencia del TGI de París ${ }^{78}$ donde se dice que este requisito solo se refiere a la divulgación con carácter internacional ${ }^{79}$, es decir, a la primera publicación.

Es importante señalar que este es un requisito que el legislador español introdujo motu proprio, no lo trasladó de la Directiva 2001/29. El artículo 5.2 b) de la directiva no recoge

73 MUÑOZ VICO, A., «¿Hacia una copia privada en la nube? Comentario a la sentencia del Tribunal de Justicia de la Unión europea de 29 de noviembre de 2017 en el asunto C-265/16», ob. cit., p. 68.

74 MUÑOZ VICO, A., «¿Hacia una copia privada en la nube? Comentario a la sentencia del Tribunal de Justicia de la Unión europea de 29 de noviembre de 2017 en el asunto C-265/16», ob. cit., pp. 70-71.

75 Conclusiones del Abogado General Maciej Szpunar (7 de septiembre de 20171). VCAST Limited contra R.T.I. S.p.A, C-265/16. Apartado 25, página 7 de la versión electrónica.

76 GARROTE FERNÁNDEZ-DÍEZ, I., en BERCOVITZ RODRÍGUEZ-CANO, R., Comentarios a la Ley de Propiedad Intelectual, 4. ${ }^{\text {a }}$ ed., ob. cit., p. 592-593.

77 GARROTE FERNÁNDEZ-DÍEZ, I., La reforma de la copia privada en la ley de propiedad intelectual, Granada (Comares), 2005, p. 136.

78 Sentencia del TGI de París 3e ch., de 10 de mayo de 1996.

79 LÓPEZ MAZA, S., Límites del derecho de reproducción en el entorno digital, ob. cit., p. 190. 
este requisito puesto que el legislador europeo decidió no armonizar los derechos morales de los autores y de otros sujetos protegidos.

\section{Por personas físicas para uso privado}

Como he expuesto anteriormente solo las personas físicas pueden ser beneficiarias del límite de copia privada. Este ha sido el punto donde el legislador ha fallado a la hora de construir el preceptivo sistema de compensación, puesto que se le imponía no solo a las personas físicas, sino también a las jurídicas, que en ningún caso son beneficiarias de este límite $^{80}$. Al ser las personas físicas las únicas beneficiarias de este límite, el subapartado a) del artículo 31.2 establece, como consecuencia, que la finalidad de la copia privada tiene que ser un uso «exclusivamente privado», y por contraposición no podrá tener un uso «profesional ni empresarial, y sin fines directa ni indirectamente comerciales».

Dilucidar qué es un uso exclusivamente privado y qué no ha supuesto un grave problema y es el origen de acaloradas discusiones entre los autores de la doctrina, así como en la jurisprudencia. Existe la duda de si un uso familiar y compartido entra dentro del concepto de uso privado, incluso si el ámbito de aplicación del 31.2 se extiende a las copias que posteriormente van a ser donadas a personas del círculo familiar o cercano del beneficiario del límite. Para averiguarlo hay que prestar especial atención al tenor literal del precepto, a las palabras que usa y a las que no usa. Usa el adverbio "exclusivamente», lo cual puede llevar a pensar que en ningún caso el beneficiario del límite puede hacer una utilización colectiva dentro de su círculo familiar y cercano. Sin embargo, usa la palabra "privado», que es mucho más amplia en su interpretación que la palabra "personal" tanto, parece que quedan amparadas por este límite las reproducciones que cumplan todos los requisitos de la copia privada y que sean objeto de una utilización colectiva dentro de un círculo familiar y cercano ${ }^{82}$. De hecho, si consultamos el trámite aprobación de la Ley 22/1987 se prefiere expresamente el término "privado" antes que "personal". De esta manera, siguiendo un criterio teleológico podría decirse que la intención del legislador es que el límite de copia privada ampare las reproducciones que tienen un uso colectivo mínimo dentro de ese círculo ${ }^{83}$. Así: «[...] siempre que se mantenga dentro de los límites de ese círculo, la reproducción puede ser objeto de distribución o de comunicación al público» ${ }^{84}$.

\footnotetext{
80 Curia: STJUE del 21 de octubre de 2010, Padawan, C-467/08, EU:C:2010:620

81 LÓPEZ MAZA, S., Limites del derecho de reproducción en el entorno digital, ob. cit., p. 190.

82 GARROTE FERNÁNDEZ-DÍEZ, I., en BERCOVITZ RODRÍGUEZ-CANO, R., Comentarios a la ley de propiedad intelectual, $3 .^{\mathrm{a}}$ ed., ob. cit., p. 561.

83 GARROTE FERNÁNDEZ-DÍEZ, I., en BERCOVITZ RODRÍGUEZ-CANO, R., Comentarios a la Ley de Propiedad Intelectual, 4. ${ }^{\mathrm{a}}$ ed., ob. cit., p. 593, nota 53.

84 MARÍN LÓPEZ, J. J., «La copia privada frente a las medidas tecnológicas de protección», Pe. i.: Revista de Propiedad Intelectual, núm. 20, 2005, p. 13 de la versión electrónica.
} 
Hablando en términos de economía legislativa resultaría inútil proscribir el uso familiar de las copias privadas debido a la enorme dificultad de controlar que se cumpla ${ }^{85}$.

La ley española no determina si un fin académico o profesional entra dentro del uso privado. Se podría considerar que los fines profesionales son fines indirectamente comerciales o lucrativos, por lo que quedarían fuera del ámbito de aplicación. Pero hay ciertos usos académicos -como el profesor que reparte copias de obras a sus alumnos-que podría discutirse si entran dentro del límite ${ }^{86}$.

Parece que el legislador español es más restrictivo que el europeo, pues el primero hace uso del pronombre posesivo «su». Podría pensarse que establecer que las copias deben ser «exclusivamente para su uso privado» acarrea menos posibilidades de uso, sin embargo, en la práctica las consecuencias son las mismas ${ }^{87}$.

Después se hace un añadido estableciendo que no cabe un uso «profesional ni empresarial» y también se le añade «sin fines directa ni indirectamente comerciales», tenor tomado directamente de la Directiva 2001/29. La intención del legislador es reforzar el límite de copia privada de acuerdo con la jurisprudencia europea, especialmente con lo establecido en la Sentencia Padawan ${ }^{88}$. Realmente el término de fines directa o indirectamente comerciales resulta mucho más protector de los derechos de su titular puesto que: «abarca cualquier género de beneficio comercial, incluso no monetario ${ }^{89} »$. Parece difícil imaginarse un supuesto en el que haya un beneficio comercial indirecto por la realización de copias privadas. En cualquier caso, si existiese un supuesto donde el aquel que realiza la copia se beneficiase indirectamente de la realización de copias privadas, probablemente su actuación ya se encontraría fuera del amparo del límite gracias a cualquiera de los otros requisitos, especialmente por la prohibición de uso colectivo o lucrativo. El profesor Marín López nos recuerda: «No es un fin indirectamente comercial, en el sentido de la Directiva, el ahorro de dinero que para la persona fisica supone realizar una copia privada en lugar de adquirir un original ${ }^{90} \gg$.

\section{Acceso legal y fuente lícita}

El subapartado b) fue la única modificación que el mencionado RDL 12/2017 hizo en el artículo 31.2., añade al «acceso legal» el concepto de «fuente lícita». La Ley 21/2014

85 GARROTE FERNÁNDEZ-DÍEZ, I., en BERCOVITZ RODRÍGUEZ-CANO, R., Comentarios a la ley de propiedad intelectual, 3. ${ }^{a}$ ed., ob. cit., p. 561.

${ }^{86}$ LÓPEZ MAZA, S., Límites del derecho de reproducción en el entorno digital, ob. cit., p. 199.

87 LÓPEZ MAZA, S., Límites del derecho de reproducción en el entorno digital, ob. cit., p. 192.

88 GARROTE FERNÁNDEZ-DÍEZ, I., en BERCOVITZ RODRÍGUEZ-CANO, R., Comentarios a la Ley de Propiedad Intelectual, 4. ${ }^{\text {a }}$ ed., ob. cit., p. 593.

${ }_{89}$ MARTÍN SALAMANCA, S., en RODRÍGUEZ TAPIA, J. M., Comentarios a la ley de propiedad intelectual, ob. cit., p. 282.

90 MARÍN LÓPEZ, J. J., «La copia privada frente a las medidas tecnológicas de protección», ob. cit., p. 14 de la versión electrónica. 
acotaba el significado de este término a tan solo dos supuestos: la compraventa en establecimiento mercantil y la reproducción de obras a las que se accede a través de un acto legítimo de comunicación pública siempre y cuando no se haya obtenido la reproducción en un espacio no autorizado. El mencionado RDL 12/2017 elimina esos supuestos y establece que para que una reproducción sea copia privada debe ser realizada «a partir de una fuente lícita» y no debe «vulnerar las condiciones de acceso a la obra o prestación».

El requisito de acceso legal ya aparece en nuestro ordenamiento desde 2006, cuando se transpuso la Directiva 2001/29, aunque no apareciese en ella. La normativa europea no reconocerá que para que haya copia privada la reproducción debe ser hecha a partir de una fuente lícita hasta 2014, cuando el TJUE en la Sentencia ACI Adam establece que: «[...] el Derecho de la Unión, en particular el artículo 5, apartado 2, letra b), de la Directiva 2001/29, en relación con el apartado 5 de dicho artículo, debe interpretarse en el sentido de que se opone a una norma nacional, [...], que no distingue la situación en la que la fuente a partir de la que se realiza una reproducción para uso privado es lícita de aquella en la que dicha fuente es ilícita ${ }^{91} \gg$. El Tribunal llegó a esta conclusión tras aplicar la regla de los tres pasos del artículo 5.5 de la directiva y comprobar que, efectivamente, amparar como copia privada las reproducciones hechas de fuentes ilícitas va contra los intereses de los derechohabientes, obstruye el buen funcionamiento del mercado interior y daña el justo equilibrio entre los titulares de derechos y los usuarios de las obras ${ }^{92}$. Esta doctrina fue reiterada posteriormente en la Sentencia Reprobel ${ }^{93}$.

La redacción actual del artículo 31.2 b) establece que para que la reproducción sea amparable por copia privada debe ser legal en el acceso y debe hacerse a partir de una fuente lícita. Se considerará fuente lícita la obra protegida que haya sido introducida en el mercado con la correspondiente autorización del titular de derechos o de otras obras lícitas ${ }^{94}$. Este es un criterio subjetivo, se tiene en cuenta la buena fe del adquirente. Dado que habitualmente las reproducciones ilícitas provienen de páginas de descarga sin autorización P2P o del llamado top manta, los usuarios suelen conocer la licitud o no de la reproducción que obtienen y por tanto no debería ser un problema para ellos si les está permitido copiarla para uso privado o no.

La nueva redacción supone una clara mejora respecto a lo establecido en 2014 gracias a su amplitud. A diferencia del régimen anterior, el nuevo régimen ampara las copias que se hacen de ejemplares alquilados, prestados o comprados en lugares distintos a un establecimiento mercantil. Respecto a la comunicación pública, siempre y en todo lugar se deben cumplir las normas del establecimiento, por tanto, la reproducción no autorizada de

\footnotetext{
91 Curia: STJUE del 10 de abril de 2014, ACI Adam, C-435/12, EU:C:2014:254. Apartado 58.

92 El profesor BERCOVITZ RODRÍGUEZ-CANO, R., en VV. AA., La reforma de la Ley de Propiedad Intelectual, ob. cit., p 74 .

93 Curia: STJUE del 12 de noviembre de 2015, Reprobel, C-572/13, EU:C:2015:750

94 GARROTE FERNÁNDEZ-DÍEZ, I., en BERCOVITZ RODRÍGUEZ-CANO, R., Comentarios a la Ley de Propiedad Intelectual, 4. ${ }^{\text {a }}$ ed., ob. cit., p. 597.
} 
una película o de una representación teatral no está considerada copia privada ya que las condiciones de acceso son vulneradas ${ }^{95}$.

\section{Prohibición de utilización colectiva o lucrativa}

Este subapartado c) nace como refuerzo del subapartado a). Si este último establece que la copia privada solo puede tener un uso privado, entonces por contraposición se prohíbe "Que la copia obtenida no sea objeto de una utilización colectiva ni lucrativa, ni de distribución mediante precio». Es un apartado un tanto repetitivo que verbaliza las consecuencias lógicas del subapartado a), por lo que no añade nada que no se pudiese prever.

Se legisla mediante la contraposición de términos, el uso colectivo, lógicamente, es un uso no privado. A efectos de este precepto la palabra "privado" no tiene el mismo significado que comúnmente se le atribuye puesto que su ámbito de aplicación incluye ese círculo familiar y cercano del que se ha hablado anteriormente. Como consecuencia el «uso colectivo» será todo acceso a la copia privada por una pluralidad indeterminada de personas que no entren dentro de ese círculo ${ }^{96}$.

También se establece como prohibición de uso: «Que la copia obtenida no sea objeto de una utilización colectiva ni lucrativa, ni de distribución mediante precio». Aquí se desarrolla lo que el subapartado a) describía como fines directa o indirectamente comerciales. La finalidad de este precepto es evitar la creación de un mercado de copias privadas, puesto que, si este límite lo permitiera, se estaría violando la regla de los tres pasos del artículo 5.5 de la Directiva 2001/29, ya que se perjudicarían los intereses de los derechohabientes ${ }^{97}$.

Los préstamos y donaciones necesitarán de dos requisitos para que puedan ser englobados en el ámbito de aplicación de la copia privada. Estos requisitos son: que no medie precio y que los prestatarios y donatarios entren dentro del círculo familiar y cercano del beneficiario del límite.

Según el profesor Bercovitz resulta repetitivo y perturbador el hecho de que el tenor de este precepto incluya los términos «lucrativo» y "distribución mediante precio» ${ }^{98}$. Esto se debe a que todo supuesto de distribución mediante precio queda englobado por el término «lucrativo».

95 GARROTE FERNÁNDEZ-DÍEZ, I., en BERCOVITZ RODRÍGUEZ-CANO, R., Comentarios a

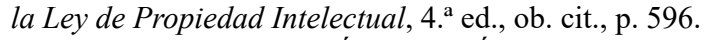

96 GARROTE FERNÁNDEZ-DÍEZ, I., La reforma de la copia privada en la ley de propiedad intelectual, ob. cit., p. 137.

97 LÓPEZ MAZA, S., Límites del derecho de reproducción en el entorno digital, ob. cit., p. 226.

98 BERCOVITZ RODRÍGUEZ-CANO, R., en VV. AA., La reforma de la Ley de Propiedad Intelectual, ob. cit., p 77. 


\section{Las exclusiones del artículo 31.3}

Este apartado aparece con la mencionada Ley 21/2014 y fue respetado íntegramente por el RDL 12/2017. Dentro del apartado 3 los subapartados b) y c) ya aparecían desde 2006, la novedad fue el apartado a).

El subapartado a) proscribe de la aplicación del artículo 31.2 a «las reproducciones de obras que se hayan puesto a disposición del público conforme al artículo 20.2.i), de tal forma que cualquier persona pueda acceder a ellas desde el lugar y momento que elija, autorizándose, con arreglo a lo convenido por contrato, $y$, en su caso, mediante pago de precio, la reproducción de la obra.». El artículo al que se remite se refiere a la puesta a disposición de obras «por procedimientos alámbricos o inalámbricos». La finalidad de este artículo es desamparar las reproducciones de obras a las que se ha accedido a través de internet, es decir, servicios de descarga on line ${ }^{99}$, siempre que dicho servicio cuente con la preceptiva licencia y autorización del autor. En caso de no existir dicha licencia la reproducción tampoco estaría amparada por el límite de copia privada, pero además se incurriría en un delito de piratería, por lo que el asunto sería penal. Se necesitan dos elementos para que se dé esta exclusión de la aplicación del límite de copia privada. Estos requisitos son: interactividad (entendida como la posibilidad de que el beneficiario del límite acceda a la obra donde y cuando él decida) y contrato on line. Si no se da uno o ambos elementos no se aplica la exclusión de modo que la reproducción estará amparada por el límite de copia privada siempre y cuando cumpla todos los requisitos anteriormente explicados ${ }^{100}$.

Los subapartados b) y c) excluyen a dos tipos concretos de obra del ámbito de aplicación del límite de copia privada, sin importar que se den todos los requisitos anteriormente mencionados. De este modo, si se quieren realizar copias de estos tipos de obras se necesitará en todo caso la autorización de autor. Los tipos de obra a los que se refiere el artículo 31.3 b) y c) son «las bases de datos electrónicas y los programas de ordenador en aplicación de la letra a) del artículo 99». Si bien las bases de datos electrónicas no pueden ser en ningún caso objeto de reproducción con fines privados, sí lo podrán ser las bases de datos no electrónicas en virtud del artículo 34.2 a) TRLPI. A los efectos de este artículo se entiende por programa de ordenador lo que establece el artículo 96.1 TRLPI ("toda secuencia de instrucciones o indicaciones destinadas a ser utilizadas, directa o indirectamente, en un sistema informático para realizar una función o una tarea o para obtener un resultado determinado, cualquiera que fuere su forma de expresión y fijación»). En el artículo 4 de la Directiva 91/250/CEE del Consejo, de 14 de mayo de 1991, sobre la protección jurídica de programas de ordenador, se establece que toda reproducción de un programa de ordenador necesitará la autorización del autor, aunque tenga como finalidad

99 BERCOVITZ RODRÍGUEZ-CANO, R., en VV. AA., La reforma de la Ley de Propiedad Intelectual, ob. cit., p. 77.

${ }_{100}$ Ambos elementos son recogidos por GARROTE FERNÁNDEZ-DÍEZ, I., en BERCOVITZ

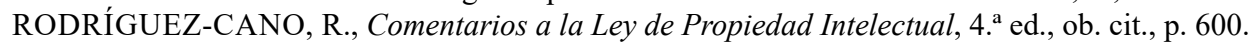


el uso privado de la misma. Presentan especial problema los programas de ordenador que también implican la utilización de otro tipo de obra como una obra audiovisual (sucede a menudo con los videojuegos). No está claro si esta otra obra que va unida al programa de ordenador se puede reproducir. Este otro tipo de obra solo podrá ser reproducida con fines privados en tanto en cuanto su reproducción no implique la reproducción del programa de ordenador, es decir, se sigue un criterio de separabilidad ${ }^{101}$.

\section{8. Últimas modificaciones}

Parece que desde que el legislador optó por regresar al sistema de canon por copia privada, este límite ya no está tan sujeto a polémicas y discusiones doctrinales. En otras palabras, el sistema de copia privada en España ha ganado cierta estabilidad. Tras las profundas reformas llevadas a cabo en 2017, el legislador español está decidido a mejorar el sistema de compensación por copia privada. El pasado año se aprobó el Real Decreto-ley 2/2018, de 13 de abril, por el que se modifica el texto refundido de la Ley de Propiedad Intelectual, aprobado por el Real Decreto Legislativo 1/1996, de 12 de abril, y por el que se incorporan al ordenamiento jurídico español la Directiva 2014/26/UE del Parlamento Europeo y del Consejo, de 26 de febrero de 2014, y la Directiva (UE) 2017/1564 del Parlamento Europeo y del Consejo, de 13 de septiembre de 2017. En este Real Decreto-ley, entre otras cosas, se añade un párrafo al apartado 8 del artículo 25. El RDL 2/2018 introduce un plazo para ejercer la acción de reembolso de la compensación equitativa por copia privada ${ }^{102}$. La acción de reembolso es un procedimiento disponible para aquellos sujetos que no pueden ser beneficiarios del límite de copia privada. La finalidad de esta acción consiste en la recuperación de las cantidades pagadas en concepto de compensación equitativa por copia privada por parte de estos sujetos.

Por otro lado, el 11 de noviembre de 2018 se publicó en el Boletín Oficial del Estado el Real Decreto 1398/2018, de 23 de noviembre, por el que se desarrolla el artículo 25 del texto refundido de la Ley de Propiedad Intelectual, aprobado por el Real Decreto Legislativo 1/1996, de 12 de abril, en cuanto al sistema de compensación equitativa por copia privada. Esta disposición tiene por objeto el desarrollo del artículo 25 del TRLPI. Concretamente desarrolla el procedimiento para obtener el certificado de exceptuación del pago de la compensación equitativa para los casos señalados en el mencionado artículo 25.7. Adicionalmente, se regula un procedimiento de resolución de conflictos entre las entidades de gestión y los solicitantes de este certificado.

Como conclusión, es posible deducir que la finalidad de ambas normas es que realmente las personas no sujetas al pago del canon no lo paguen. Por ende, queda claro, que el

${ }^{101}$ GARROTE FERNÁNDEZ-DÍEZ, I., en BERCOVITZ RODRÍGUEZ-CANO, R., Comentarios a la Ley de Propiedad Intelectual, 4. ${ }^{\text {a }}$ ed., ob. cit., p. 599.

102 BERCOVITZ RODRÍGUEZ-CANO, R., «La accidentada vida de la legislación de propiedad intelectual», Revista Doctrinal Aranzadi Civil-Mercantil, núm. 6, p. 1 de la versión electrónica. 
legislador quiere mantener este límite en un futuro y además hacerlo dentro de los parámetros europeos impidiendo que personas no beneficiarias del límite paguen su compensación, que ha sido en lo que ha fallado siempre el legislador español.

\section{CONCLUSIONES}

El límite de copia privada tiene un largo recorrido, no solo en España, sino también en Europa. A lo largo de esta andadura ha sufrido numerosas alteraciones con el objetivo de adaptarlo a las circunstancias del momento. Es curioso destacar que, a diferencia de en el resto de los Estados Miembros de la Unión Europea, solo en España este límite ha estado sujeto a tan numerosas polémicas, reformas y llamadas de atención por parte del Tribunal de Justicia de la Unión Europea. Este dificultoso camino de la copia privada en España es debido a una mala política legislativa provocada por una falta absoluta de escucha y de atención por parte del legislador español. En 2010, tras la sentencia Padawan del Tribunal de Justicia de la Unión Europea, el legislador optó por destruir el sistema de compensación equitativa por copia privada y construir desde cero uno nuevo con cargo a los PPGGE para adecuarlo a la legislación europea, o eso creía él. No se dio cuenta en 2011, ni tampoco en 2012 al aprobar el RDL 1657/2012, que no era el sistema de canon lo que estaba en disconformidad con el Derecho Europeo sino el hecho de que este se aplicase indiscriminadamente a personas que no debían pagarlo, y eso que la Sentencia Padawan estaba muy clara. De este modo, el legislador español decidió crear un sistema nuevo que repetía los errores del anterior, pero de otra manera. El Tribunal de Justicia de la Unión Europea repitió otra vez lo mismo en la Sentencia EGEDA y otros en 2016: que no se debe imponer la compensación equitativa por copia privada a aquellos que no se benefician de ella, esencialmente a las personas jurídicas. El legislador español volvió a tropezar con la misma piedra y la Unión Europea le tuvo que volverle a llamar la atención declarando disconforme con el Derecho Europeo el sistema de compensación equitativa. Si en 2010 se hubiese escuchado con atención lo que se decía desde Europa y no se hubiese legislado mal y rápido, la copia privada en España no habría estado sujeta a tanta discusión ni a tantos cambios inútiles.

Como conclusión, todos los cambios que se han venido dando en el límite de copia privada desde su aparición en 1987 se deben a: la armonización del derecho de propiedad intelectual a nivel europeo, a la concreción del alcance y de las condiciones en las que se da este límite y, por último y como he indicado anteriormente, por una política legislativa errónea provocada por la falta de escucha del legislador.

Pero este camino no ha acabado, la copia privada seguirá siendo objeto de polémicas y debates sobre su continuidad tal y como lo conocemos. Cabe preguntarse si hoy en día este límite sigue siendo de uso generalizado como hace años. Se observa que en los últimos años la tecnología no para de innovar permitiendo nuevas formas de acceso a obras y contenidos protegidos. Surgen novedosas formas de consumo como las plataformas digitales de mú- 
sica, cine o series (como Youtube, Netflix o Spotify) que en pocos años se han convertido en servicios de consumo generalizado. Este tipo de plataformas digitales permiten acceder a sus contenidos donde y cuando el consumidor elija. Por ende, van ganando terreno a la copia privada que se está convirtiendo en una forma más gravosa de poder disponer de la obra. Ya no es necesario tener tres copias de un disco para poder escucharlo en casa, en el coche y en el móvil, sino que, gracias a internet y a estas plataformas, se accede al mismo ejemplar online desde cualquier lado a voluntad del consumidor. Sin embargo, por otro lado, hay ciertos ámbitos donde todavía es útil, como en la investigación. Cuando investiga sobre un tema y se necesita consultar varias obras, a veces no se usa la totalidad de la obra, sino solo una parte. De este modo, sigue siendo cómodo hacer una copia para uso privado de parte de una obra.

Es notorio que el límite de copia privada ya no se usa tanto, pero sigue resultando útil. Así, su futuro es incierto. Esto se debe en gran medida al imparable desarrollo tecnológico. No sería en balde plantearse ciertas preguntas como: ¿la actual regulación de la copia privada es capaz de hacer frente a las nuevas realidades tecnológicas como por ejemplo a las impresoras 3D? Esta nueva realidad cambiará para siempre la manera de entender la propiedad intelectual y pondrá el límite de copia privada en el foco de discusión. O, por otro lado, ¿es viable el mantenimiento de este límite? De este modo, ya se empieza a plantear la necesidad de actualizar, no solo el régimen de copia privada sino también la regulación de propiedad intelectual en general, con el objetivo de aumentar su dinamismo y adaptabilidad a las nuevas realidades tecnológicas.

¿Cuál será la respuesta? El legislador europeo ha sido muy abierto en la regulación del límite de copia privada, debido al carácter facultativo de este límite. La construcción de los requisitos que se necesitan es bastante abierta para los Estados Miembros que pueden regular la copia privada como quieran, siempre dentro de unos parámetros mínimos. Por otro lado, en España el legislador ha sido más restrictivo, ha impuesto muchos requisitos que la Unión no establecía, como el de la divulgación de las obras, o la asistencia de terceros. Es indudable que se necesita un sistema que sea lo suficientemente abierto para hacer frente a todos los cambios que el desarrollo tecnológico demanda. Sin embargo, también se necesita un sistema que proteja los intereses de los creadores para mantener un derecho de la propiedad intelectual fuerte y que promocione la creación.

Parece que no existe ninguna intención por parte de los legisladores europeo y español de modificar o suprimir el límite de copia privada. El 12 de septiembre de 2018 el Parlamento Europeo aprobó el texto de la nueva Directiva 2016/0280 sobre derechos de autor en el mercado único digital. En este texto nada se dice sobre el límite de copia privada por lo que se deduce que en el seno de la Unión Europea existe un consenso por su mantenimiento. 
La copia privada seguirá siendo objeto de un fuerte debate, pero este es un límite muy necesario para los ciudadanos ya que facilita el acceso a la cultura en el ambiente familiar y privado, que es donde empieza la educación. Por tanto, es necesario mantenerlo.

\section{BIBLIOGRAFÍA}

BERCOVITZ RODRÍGUEZ-CANO, R., GARROTE FERNÁNDEZ-DÍEZ, I., GONZÁLEZ GONZALO, A. y SÁNCHEZ ARISTI, R., Las reformas de la ley de propiedad intelectual, Valencia (Tirant Lo Blanch), 2006.

BERCOVITZ RODRÍGUEZ-CANO, R., Comentarios a la ley de propiedad intelectual, 3. ${ }^{\text {a }}$ ed., Madrid (Tecnos), 2007.

BERCOVITZ RODRÍGUEZ-CANO, R., «Las limitaciones y excepciones a los derechos de propiedad intelectual y el equilibrio entre los intereses afectados en el Derecho español», Pe. i.: Revista de Propiedad Intelectual, núm. extra 1, 2011, pp. 13-28.

BERCOVITZ RODRÍGUEZ-CANO, R., Manual de propiedad intelectual, 6. ${ }^{\mathrm{a}}$ ed., Valencia (Tirant lo Blanch), 2015.

BERCOVITZ RODRÍGUEZ-CANO, R., «Más sobre la copia privada. Revista Doctrinal», Aranzadi Civil-Mercantil, núm. 3, 2015, pp. 127-131.

BERCOVITZ RODRÍGUEZ-CANO, R., Comentarios a la Ley de Propiedad Intelectual, 4. ${ }^{\mathrm{a}}$ ed., Madrid (Tecnos), 2017.

BERCOVITZ RODRÍGUEZ-CANO, R., «La accidentada vida de la legislación de propiedad intelectual», Revista Doctrinal Aranzadi Civil-Mercantil, núm. 6, 2018, pp. 87-92.

BERCOVITZ RODRÍGUEZ-CANO, R., «Copias privadas en la nube y comunicación pública», Revista Doctrinal Aranzadi Civil-Mercantil, núm. 3, 2018, pp. 21-26.

CASAS VALLÉS, R., «La fotocopia y su régimen jurídico», Aranzadi Civil, núm. 1, 1993, pp. 2000-2003.

GARROTE FERNÁNDEZ-DÍEZ, I., La reforma de la copia privada en la ley de propiedad intelectual, Granada (Comares), 2005.

GONZÁLEZ GARCÍA, A., «La compensación equitativa por copia privada digital», Actualidad Jurídica Uría Menéndez, núm. 15, 2006, pp. 31-44. 
GÓNZALEZ SAQUERO, P., «Reseña de la Sentencia en el asunto C-265/16 VCAST Limited / RTI SpA (TJCE 2017, 218)», Revista Española de Derecho Europeo, núm. 65, 2018.

GOTZEN, F. y MINERO ALEJANDRE, G., «Comentario a la estrategia de la Comisión Europea para 2011-2014 en materia de propiedad intelectual, "Un mercado común para los derechos de propiedad intelectual"», Pe. i.: Revista de Propiedad Intelectual, núm. 38, 2011, pp. 127-139.

JIMÉNEZ SERRANÍA, V., «La "sentencia sobre el canon": vicios y virtudes del sistema de compensación de copia privada en España, comentario a la STJUE de 21 de octubre 2010, c- 467/08, caso padawan vs. SGAE», Revista General de Derecho Europeo, núm. 22, 2010.

LÓPEZ MAZA, S., Limites del derecho de reproducción en el entorno digital, Granada (Comares), 2009.

MARÍN LÓPEZ, J. J., «La copia privada frente a las medidas tecnológicas de protección», Pe. i.: Revista de Propiedad Intelectual, núm. 20, 2005, pp. 9-76.

MUÑOZ VICO, A., «¿Hacia una copia privada en la nube? Comentario a la sentencia del Tribunal de Justicia de la Unión europea de 29 de noviembre de 2017 en el asunto C-265/16», Pe. i.: Revista de Propiedad Intelectual, núm. 57, 2017.

RODRÍGUEZ TAPIA, J. M., Comentarios a la ley de propiedad intelectual, 2. ${ }^{a}$ ed., Pamplona (Civitas Thomson Reuters), 2010.

SÁNCHEZ ARISTI, R., «El renovado sistema de compensación equitativa por copia privada tras el Real Decreto-Ley 12/2017», La Ley mercantil, núm. 46, 2018, p. 1.

VV. AA., Estudios sobre la Ley de Propiedad Intelectual: últimas reformas y materias pendientes, Madrid (Dykinson), 2016.

VV. AA., La reforma de la Ley de Propiedad Intelectual, Valencia (Tirant lo Blanch), 2015.

XALABARDER, R., MARTÍN-PRAT, M., MALMIERCA, M. y RAMÍREZ, J., «La copia privada digital», Revista de Internet, Derecho y Política, núm. 1, 2005, pp. 35-57.

\section{Jurisprudencia}

Europea

Curia: STJUE del 29 de noviembre de 2017, VCAST, C-265/16, EU:C:2017:913 
Curia: STJUE del 09 de junio de 2016, EGEDA y otros, C-470/14, EU:C:2016:418

Curia: STJUE del 12 de noviembre de 2015, Reprobel, C-572/13, EU:C:2015:750

Curia: STJUE del 05 de marzo de 2015, Copydan Båndkopi, C-463/12, EU:C:2015:144

Curia: STJUE del 10 de abril de 2014, ACI Adam, C-435/12, EU:C:2014:254

Curia: STJUE del 27 de junio de 2013, VG Wort y otros, C-457/11 - C460/11, EU:C:2013:426

Curia: STJUE del 16 de junio de 2011, Stichting de Thuiskopie, C-462/09, EU:C:2011:397

Curia: STJUE del 21 de octubre de 2010, Padawan, C-467/08, EU:C:2010:620

\section{Española}

CENDOJ: ROJ: STS 4832/2016. Sentencia del Tribunal Supremo 2394/2016 del 10 de noviembre de 2016 . 